\title{
Update on the role of antipsychotics in the treatment of Tourette syndrome
}

\author{
This article was published in the following Dove Press journal: \\ Neuropsychiatric Disease and Treatment \\ 9 March 2012 \\ Number of times this article has been viewed
}

\section{Daniel Huys \\ Katja Hardenacke \\ Pia Poppe \\ Christina Bartsch \\ Burak Baskin \\ Jens Kuhn \\ Department of Psychiatry and Psychotherapy, University of Cologne, Cologne, Germany \\ Head: Prof. Dr. Joachim Klosterkötter}

Correspondence: Daniel Huys Department of Psychiatry and Psychotherapy, University of Cologne, Kerpener Strasse 62, 50924 Cologne,

Germany

$\mathrm{Tel}+4922 \mid 478862$ II

Fax +49 22I 4786605

Email daniel.huys@uk-koeln.de

\begin{abstract}
Tourette syndrome (TS) is a neuropsychiatric disorder with typical onset in childhood and characterized by chronic occurrence of motor and vocal tics. The disorder can lead to serious impairments of both quality of life and psychosocial functioning, particularly for those individuals displaying complex tics. In such patients, drug treatment is recommended. The pathophysiology of TS is thought to involve a dysfunction of basal ganglia-related circuits and hyperactive dopaminergic innervations. Congruently, dopamine receptor antagonism of neuroleptics appears to be the most efficacious approach for pharmacological intervention. To assess the efficacy of the different neuroleptics available, a systematic, keyword-related search in PubMed (National Library of Medicine, Washington, DC) was undertaken. Much information on the use of antipsychotics in the treatment of TS is based on older data. Our objective was to give an update and therefore we focused on papers published in the last decade (between 2001 and 2011). Accordingly, the present review aims to summarize the current and evidence-based knowledge on the risk-benefit ratio of both first and second generation neuroleptics in TS.
\end{abstract}

Keywords: Tourette, Tourette syndrome, neuroleptics, antipsychotics

\section{Introduction}

Tourette syndrome (TS) is a serious, often intractable neuropsychiatric disorder characterized by enduring though waxing and waning phonic (vocal) and motor tics. Contrary to the earlier perception of TS as a psychogenic disorder, its neurobiological basis has been proven, although the exact mechanisms are not yet fully understood. ${ }^{1}$ Once tics have emerged, usually by the age of about 6-8 years, they reach a maximum at around 12 years. About $40 \%$ of all TS patients show a gradual to complete spontaneous remission of symptoms in early adulthood. ${ }^{2}$ Drug treatment is recommended for children who suffer from severe tics and adults with persistent and significantly impairing symptoms as a result of TS.

The pathophysiology is thought to involve a dysfunction of basal ganglia-related circuits and hyperactive dopaminergic innervations. ${ }^{3}$ Studies supporting the strong hypothesis of an imbalance in the dopaminergic system have shown an increased number of striatal ${ }^{4}$ and cortical ${ }^{5}$ dopamine receptors, as well as altered dopamine binding properties in the basal ganglia. ${ }^{6,7}$ Therefore, the main action of drugs used in the treatment of tics is the modulation of the dopaminergic metabolism. In this context, research is still focusing on the $\mathrm{D}_{2}$ receptor system ${ }^{5}$ and congruently $\mathrm{D}_{2}$ receptor antagonism appears to be the most efficacious approach for pharmacological intervention. ${ }^{8}$ For 40 years, the beneficial effects of $\mathrm{D}_{2}$ receptor blocking in the treatment of tics have been reported, with an average success rate of $70 \% .{ }^{9}$ In general, typical or first generation 
antipsychotics are thought to have a very high dopamine blocking potency. Hence, they are thought to be very effective in ameliorating tics. ${ }^{10}$ However, these agents might be associated with severe adverse events, because a strong $\mathrm{D}_{2}$ receptor antagonism is connected with high rates of extrapyramidal symptoms (parkinsonism, akathisia, tardive dyskinesia) or even hyperprolactinemia. Furthermore, they also alter cholinergic, serotonergic, histaminergic, and alpha-adrenergic transmission and thereby might lead to weight gain, drowsiness, and excessive sedation. Atypical or second generation neuroleptics usually have a greater affinity for $5-\mathrm{HT}_{2}$ receptors than for $\mathrm{D}_{2}$ receptors which is associated with fewer extrapyramidal side effects ${ }^{11}$ than seen under typical neuroleptics.

As a result of frequent adverse events caused by antipsychotics, attempts have been made to use other medications for the treatment of TS such as noradrenergic agents (clonidine, guanfacine, atomoxetine) or tetrabenazine, nicotine, tetrahydrocannabinol, talipexole, clonazepam, baclofen, levetiracetam, topiramate, lithium, or naloxone (as shown in the paper by Roessner et $\mathrm{al}^{9}$ ). As well as pharmacological treatment, psychotherapy or rather, habit reversal training ${ }^{12}$ can be helpful if patients are willing to engage in it. Finally, deep brain stimulation should be considered for therapyresistant patients because it can successfully expand the limits of medication-based treatment options. ${ }^{13}$

\section{Methods}

Given the big impact of neuroleptics in the treatment of TS, the intention of this review is to give an update on the evidence-based, risk-benefit ratio of the different available antipsychotics.

Therefore, a systematic literature search was carried out in PubMed including articles published from 2001 to May 2011. The search terms were "antipsychotics and Tourette syndrome" plus "neuroleptics and Tourette syndrome". By using a combination of these search terms we identified 175 articles published in German or English. In the first step, all titles and abstracts were screened carefully for aspects relevant to our main topic. Our second step was an analysis of the full texts to identify valuable information. In this process, we checked whether the information presented was collected in clinical studies with high methodological standards or from case reports or incidental findings. We used 43 articles in the present paper, found by using the research criteria described above; 132 articles were excluded. In addition, references for the identified articles were screened for further relevant literature not listed in PubMed or beyond our search period. In this way, another 89 articles were found and considered in the present review.

\section{Results \\ Typical antipsychotics \\ Haloperidol}

The butyrophenone haloperidol was the first drug used in treatment for TS and remains the most widely used agent for this indication worldwide. The first report on its empirical use in TS concerned an adult who had already undergone a frontal lobectomy. ${ }^{14}$ Haloperidol was approved by the Food and Drug Administration (FDA) for the treatment of adult TS patients in 1969 and for children in $1978 .{ }^{15}$ Due to its strong blocking effect on $\mathrm{D}_{2}$ receptors, tic reductions of $78 \%-91 \%$ at a maximum dosage of $10 \mathrm{mg}$ have been estimated. ${ }^{16,17}$ The most commonly observed adverse events are extrapyramidal reactions (parkinsonism, tardive dyskinesia), neuroleptic malignant syndrome, drowsiness, restlessness, and sexual dysfunction. In our search period, we were unable to find any valuable studies. The approval of haloperidol is based mainly on its effectiveness known from older comparison studies with pimozide, fluphenazine, and placebo. An early randomized, double-blind and placebo-controlled study showed that haloperidol and pimozide decrease tic frequency significantly. ${ }^{18}$ Some studies stated that haloperidol is superior to both placebo and pimozide. ${ }^{16}$ However, in another study including 22 patients the effect of haloperidol was described as inferior to pimozide and even to placebo. ${ }^{19}$ Yet another study suggested that treatment with haloperidol is more often discontinued than with pimozide, even though both drugs produced comparable relief of symptoms. ${ }^{20}$ Additionally, haloperidol produced significantly more acute dyskinesia/ dystonia than pimozide. Some studies suggested that other, similar, agents such as pimozide ${ }^{19}$ and fluphenazine ${ }^{21}$ may be as efficacious as haloperidol, but with fewer side effects and a slightly better patient tolerance.

Conclusion: Although the evidence is not consistent, based on clinical experience, haloperidol may be an effective agent for the treatment of TS. Older studies (data collection before 1997) suggested that it is less tolerable and is more often associated with adverse events than other typical neuroleptics. For this reason, haloperidol should be used mainly as a spare medication in severely diseased patients. $^{22}$

\section{Pimozide}

Pimozide is a $D_{2}$ receptor antagonist which in addition blocks calcium channels ${ }^{11}$ and to a lesser extent $D_{1}$ receptors. It exhibits less noradrenaline (alpha1) antagonism than haloperidol, and less sedation. ${ }^{22}$ Pimozide can be associated with severe arrhythmia and prolongation of the QTc 
interval. ${ }^{23}$ The most recent article about the efficacy of pimozide is a comprehensive Cochrane review from 2009 reporting on six randomized controlled trials with a total of 162 participants..$^{24}$ The comparison between pimozide, haloperidol, and risperidone revealed inconsistent results. Pimozide, however, was shown to be considerably more effective than placebo. Inconsistency of results is brought about by three double-blind, placebo-controlled trials of pimozide versus haloperidol: one revealed equal efficacy, another found haloperidol slightly more effective than pimozide, while yet another showed pimozide to be superior to haloperidol. Pimozide is further described as having fewer side effects (including sedation and extrapyramidal symptoms) than haloperidol. In two trials comparing pimozide with risperidone, no significant differences between the two drugs in terms of efficacy or side-effect profile could be identified. ${ }^{25,26}$

Conclusion: In our opinion, pimozide is indicated for the suppression of tics in patients who have failed to respond satisfactorily to standard treatment with the frequently recommended agent risperidone. As a rather older compound with a considerable cardiac risk profile, we support the appraisal for pimozide as a reserve treatment especially because no substantial new data have been acquired in recent years. Singer favored pimozide as second choice medication in his helpful suggestions. ${ }^{11}$

\section{Fluphenazine}

Fluphenazine acts as both $\mathrm{D}_{1}$ and $\mathrm{D}_{2}$ receptor antagonist. ${ }^{11}$ It has been used particularly in the US for many years to treat TS, though it has simply been studied systematically. Our search period included only a small amount of current data. A naturalistic follow-up study from 2004 including 41 patients indicated that treatment with fluphenazine for at least one year was safe and effective. ${ }^{27}$ A retrospective review from 2009 also showed fluphenazine to be an effective and well-tolerated therapy. ${ }^{28}$ The main data were collected in a few older studies including placebo-controlled, doubleblind trials between 1982 and 1985 which revealed that fluphenazine is effective in controlling tics, while having fewer side effects than haloperidol (small, open-label studies)..$^{29-31}$

Conclusion: Although fluphenazine has been shown to be an effective and well-tolerated therapy for TS, we would not unconditionally recommend its use due to the lack of recent studies comparing this drug to newer medications such as atypical antipsychotics. Yet, it is also favored by Singer as second choice medication. ${ }^{11}$

\section{Atypical antipsychotics \\ Benzamide}

The benzamides (tiapride, sulpiride, and amisulpride) are a class of amides of benzoic acid and further selective $\mathrm{D}_{2}$ receptor antagonists. ${ }^{32}$ Substituted benzamides are effective in the treatment of tics and it seems that the occurrence of extrapyramidal side effects is unusual. ${ }^{22}$

In Germany, benzamides (especially tiapride) are used as first-line medication in the treatment of TS, particularly in children and young adults. The lack of studies investigating the efficacy of these agents might be explained by the fact that tiapride and sulpiride are not available in the US. ${ }^{8}$

\section{Tiapride}

Tiapride has a selective antagonistic effect on $\mathrm{D}_{2}$ receptors, especially in the ventral striatum and in parts of the limbic system. ${ }^{9}$ Although this drug is in general well-suited for the treatment of hyperkinetic movement disorders which are associated with functional dopamine hyperactivity ${ }^{33}$ and is even considered as first choice in European guidelines, ${ }^{9}$ no clinical studies focusing on the treatment with tiapride in humans were found in our search period. There is only one case report from 2004 about a patient with severe side effects such as massive weight gain, hyperprolactinemia, amenorrhea, and sedation under therapy with tiapride. ${ }^{34}$ Nevertheless, there are two animal studies investigating the effects of tiapride, suggesting that this drug does not lead to long-lasting alterations of dopamine concentration or other severe short- and long-term adverse reactions in young rats. ${ }^{35,36}$ Thus evidence for its clinical efficacy in humans is mostly based on older studies. Since the 1970s, some case reports and placebo-controlled studies have reported the success of TS treatment with tiapride. ${ }^{37-39}$ Only one randomized, double-blind, and placebo-controlled crossover study from 1988 investigated the effects of tiapride in 17 children. The results yielded beneficial therapeutic effects on tic symptomatology, while no adverse effects on children's cognitive functioning were reported. ${ }^{40}$ Drowsiness, modest transient hyperprolactinemia, and moderate weight gain have been observed as side effects.

Conclusion: Despite the lack of actual studies, the treatment of TS with tiapride should still be considered, especially because of its moderate side effects, which have been confirmed by translational studies and clinical experience. ${ }^{9}$ Nevertheless, further well-designed studies and head-tohead comparisons would be desirable. 


\section{Sulpiride}

Sulpiride is a highly selective $\mathrm{D}_{2}$ and $\mathrm{D}_{3}$ receptor antagonist with antipsychotic and antidepressant mechanisms as well as anxiolytic effects. ${ }^{41}$ It was first used for the treatment of TS in $1970 .{ }^{42}$ Usually, few adverse events are reported with its use (eg, sedation and sustained drowsiness in up to $25 \%){ }^{32}$ Less frequent side effects are restlessness, as well as sleep problems $\mathrm{s}^{43}$ and depressive symptoms, which occur despite the antidepressant and mood-stabilizing effects of sulpiride. ${ }^{44}$ Increased appetite and as a consequence weight gain may occur, which is probably attributable to the stimulating effects of prolactin secretion causing galactorrhea and amenorrhea. ${ }^{45,46}$ Due to its rare extrapyramidal and vegetative side effects, sulpiride is probably one of the most prescribed medications in the treatment of tics in TS in Europe. ${ }^{18}$

One recent prospective, open-label, study investigated the effect of low-dose sulpiride treatment of children and adolescents with TS or chronic tic disorder. The 189 treated patients demonstrated a significant reduction in tic symptomatology after a period of 6 weeks. The most common adverse events were sedation ( $16 \%$ of the patients), which often disappeared 1-2 weeks after treatment onset. ${ }^{47}$ These promising results are supported by older studies. Robertson and colleagues for example documented in 1990 a positive effect of treatment with sulpiride in $59 \%$ of patients. Furthermore, besides tic reduction, a significant decrease in other phenomena such as echophenomena, aggression, subjective tension, and obsessive compulsive traits was found ${ }^{44}$ In a placebo-controlled crossover study the treatment effects of fluvoxamine and sulpiride in patients suffering from TS and obsessive compulsive disorders were compared. Sulpiride monotherapy was shown to reduce tics significantly. ${ }^{48}$

Conclusion: Given the previously described data, the treatment of mild-to-moderate TS or chronic tic disorder with sulpiride can be recommended. ${ }^{9,44}$ Even in low doses, sulpiride seems to be effective and is usually associated with few adverse events.

\section{Amisulpride}

Amisulpride is a highly selective benzamide with $10 \times$ higher affinity to $\mathrm{D}_{2}$ and $\mathrm{D}_{3}$ receptors than sulpiride and with little activity at serotonergic, histaminergic, or muscarinic receptors. ${ }^{32}$ While the agonistic effects on presynaptic $\mathrm{D}_{2} / \mathrm{D}_{3}$ receptors prevail at lower doses (increased dopamine transmission), at higher doses, amisulpride acts preferentially on postsynaptic $\mathrm{D}_{2} / \mathrm{D}_{3}$ receptors, reducing dopaminergic transmission. ${ }^{32}$
Randomized controlled studies on the treatment of TS with amisulpride are lacking. As far as we know, only three case reports have been published on the treatment of TS with amisulpride, of which one was published in French. ${ }^{49}$ The second case report describes the effective treatment of TS with moderate doses of amisulpride (maximum $400 \mathrm{mg}$ / day). One adverse event concerning amenorrhea was reported by a patient. ${ }^{50}$ Another case report on a patient with atypical TS as a tardive dyskinesia, indicated a change of medication from olanzapine to amisulpride. ${ }^{51}$

Conclusion: Because of the lack of randomized controlled studies, amisulpride cannot be recommended as first-line medication for the treatment of TS. Amisulpride could be seen as a second-choice medication given several expert opinions. ${ }^{32}$ Further studies are necessary to obtain valid results on its effectiveness.

\section{Clozapine}

Clozapine was first introduced in Europe in 1971, and was approved by the FDA to treat refractory schizophrenia in 1989. ${ }^{52}$ It acts as a $5-\mathrm{HT}_{2 \mathrm{~A}}, 5-\mathrm{HT}_{2 \mathrm{C}}$, and 5- $\mathrm{HT}_{3}$ antagonist and, to a lesser extent, as a $\mathrm{D}_{1}$ antagonist. ${ }^{9}$ It has only a weak $\mathrm{D}_{2}$ blocking effect and may therefore be less effective in treating tics than other antipsychotics. A few older studies reported successful reductions in tics during monotherapy (as shown by Jaffe et $\mathrm{l}^{53}$ in the context of tardive TS) or in combination with propanolol or tetrabenazine. ${ }^{54}$ However, clozapine has not been found helpful in the treatment of TS as stated by several case reports which also documented serious adverse events (eg, agranulocytosis) associated with this agent. ${ }^{55}$ Furthermore, the occurrence of stuttering, facial tics, myoclonic seizures, ${ }^{56}$ and even the exacerbation of tics seems to be related to the administration of clozapine. ${ }^{57}$

Conclusion: Due to the lack of efficacy and its potentially severe side effects, we would not recommend clozapine for the treatment of TS symptoms.

\section{Risperidone}

Risperidone acts as a 5- $\mathrm{HT}_{2}$ receptor antagonist at low doses and as a $\mathrm{D}_{2}$ antagonist at higher doses. ${ }^{58} \mathrm{It}$, too, has moderateto-high affinity for $\alpha 1$-adrenergic, $\mathrm{D}_{3}, \mathrm{D}_{4}$, and $\mathrm{H}_{1}$-histamine receptors. ${ }^{11}$ Risperidone can prolong the QTc interval, and weight gain can be an emerging problem. ${ }^{58-61}$ Our search period includes many well-executed studies. Bruggeman and colleagues suggest that risperidone may improve tic symptoms in $30 \%-62 \%$ of patients ${ }^{25}$ although some studies have reported even greater success rates. ${ }^{62}$ The efficacy 
of risperidone has been confirmed by two randomized, double-blind, placebo-controlled trials. ${ }^{63,64}$ Furthermore, risperidone was found to be equally effective or possibly slightly more effective than pimozide in two randomized, double-blind, crossover studies. ${ }^{25,26}$ Compared with haloperidol, risperidone showed slightly better tic reduction ( $28 \%$ vs $21 \%$ ) but the difference in efficacy between the two drugs was not significant. ${ }^{65}$ In a randomized, double-blind study, risperidone and clonidine appeared equally effective in the treatment of tics. ${ }^{66}$ Additionally, many older studies reported a positive response ${ }^{67-70}$ with a similar efficacy to haloperidol. A high discontinuation rate seems to be one major drawback in the use of risperidone. It is suggested that only $20 \%-30 \%$ of patients can tolerate the use of this medication in the long term due to the associated side effects. ${ }^{71}$ Risperidone was also effective in treating obsessivecompulsive symptoms..$^{25,66,72}$ Moreover, risperidone could also be useful in ameliorating aggressive behaviour. ${ }^{73,74}$

Conclusion: The effectiveness of risperidone has been proven in several studies with high methodical demands. It seems that this drug is as effective as haloperidol in treating tics and may be also effective in treating comorbidities like obsessive-compulsive and aggressive symptoms. Therefore, we recommend risperidone as standard therapy. An unfavorable aspect of risperidone is the high discontinuation rate which may be due to common adverse events like fatigue, somnolence, and weight gain. ${ }^{22}$

\section{Olanzapine}

Olanzapine is an atypical neuroleptic with moderate-to-high affinity for $\mathrm{D}_{2}, \mathrm{D}_{4}, 5-\mathrm{HT}_{2 \mathrm{~A}}, 5-\mathrm{HT}_{2 \mathrm{C}}$, and $\alpha-1$ adrenergic receptors, as well as $\mathrm{D}_{1}$ receptors. ${ }^{75}$ Compared with other antipsychotics, olanzapine has greater activity at serotonin $5-\mathrm{HT}_{2}$ receptors than at $D_{2}$ receptors, ${ }^{76}$ which may explain the few extrapyramidal effects. A lower incidence of hyperprolactinemia than with typical antipsychotic agents or risperidone could be explained by the presumption that this drug does not appear to block dopamine within the tuberoinfundibular tract. The most widely reported adverse reactions were drowsiness/ sedation and increased appetite, frequently followed by weight gain. ${ }^{77,78}$ Because of metabolic adverse reactions, caution is recommended in case of hyperglycemia and diabetes. Recently published open-label trials have shown improvement in tic scores. ${ }^{76,77}$ In 60 children treated for 4 weeks with either olanzapine or haloperidol, efficacy in terms of tic severity reduction and global clinical impression was found to be $74 \%$ for both groups, though olanzapine was associated with fewer side effects. ${ }^{81}$ Other studies indicated that olanzapine leads to significant reductions in tic severity and even in aggression. The only identified drawback was weight gain. ${ }^{75}$ In an older, double-blind, crossover study, olanzapine seemed to be better at reducing tics in four patients with severe tics compared with low-dose pimozide. ${ }^{80}$ In addition, several older case reports ${ }^{81-84}$ and open-label studies ${ }^{85,86}$ have suggested efficacy of olanzapine in the treatment of TS in adolescents and adults.

Conclusion: The major drawback of olanzapine is the valid concern about adverse metabolic effects and weight gain as known from the treatment of schizophrenia and bipolar disorder. Apart from this, the early use of olanzapine to treat TS can be recommended based on studies which have shown olanzapine to be as effective as haloperidol or pimozide. Additionally, this drug can reduce symptoms of ADHD and $\operatorname{aggression}^{22}$

\section{Quetiapine}

Quetiapine antagonizes 5- $\mathrm{HT}_{1 \mathrm{a}}, 5-\mathrm{HT}_{2}, \mathrm{D}_{2}$, histamine $\mathrm{H}_{1}$, and $\alpha 1$ and $\alpha 2$ adrenergic receptors. ${ }^{11} \mathrm{Up}$ to now, its efficacy for tic suppression is based solely on case reports which include, for example, the effective treatment of two children with TS. ${ }^{87}$ In an open-label trial with twelve children, quetiapine reduced tics significantly. ${ }^{88}$ In the beginning, the main adverse event was sedation. During the 8 weeks under investigation, patients did not experience extrapyramidal adverse reactions and no statistically significant weight gain. Quetiapine reduced tic severity scores by over $60 \%$ after week 4 in a retrospective review of 12 patients of ages $8-18$ years in which, contrary to the study mentioned before, the only noteworthy adverse reaction was increased weight. ${ }^{89}$

Conclusion: The few available studies which mainly concentrate on patients under 18 years suggest that quetiapine could be effective in the treatment of TS and is associated with a tolerable side-effect profile, although weight gain and fatigue are fairly common. Due to the lack of methodologically wellexecuted studies, no further statement can be given.

\section{Ziprasidone}

Ziprasidone pharmacological actions work by $\mathrm{D}_{2}$ and 5-HT antagonism and blocking other neurotransmitters such as norepinephrine, serotonin, and adrenaline. It also has a moderate affinity for $\mathrm{H}_{1}$ receptors. The near absence of weight gain makes it attractive for the treatment of TS in obese patients. ${ }^{90}$ Generally, ziprasidone has a higher risk for prolongation of the QT-interval than other compounds such as risperidone, olanzapine, or haloperidol. ${ }^{11}$ The most frequently reported adverse event is a mild transient somnolence. ${ }^{91,92}$ An open-label study including 
24 children and adolescents with tic disorders indicated that a single dose of ziprasidone was well tolerated without clinically significant effects on electrocardiogram..$^{93}$ Efficacy was evaluated in an older, randomized, double-blind, placebocontrolled study including 28 children and adolescents, where ziprasidone appeared to be significantly more effective than placebo in reducing tics and was well tolerated. ${ }^{91} \mathrm{~A}$ case report described the induction of tardive symptoms in a 28-year-old patient suffering from vocal tics secondary to treatment with ziprasidone. Additionally, anxiety and tension seemed to be aggravated by an increase in the drug. However, vocal tics resolved approximately 4 days after cessation. ${ }^{94}$

Conclusion: Although the availability of recent data is too restricted to draw a final conclusion, ziprasidone could be used as an attempt if first-line medication was not effective. Apart from QT-prolongation, this drug has a favorable sideeffect profile and initial promising results give hope for upcoming studies.

\section{Aripiprazole}

Aripiprazole is one of the newest antipsychotics with a unique mechanism of action since it works as a partial agonist on the $\mathrm{D}_{2}$ receptors. ${ }^{22}$ It also has a high affinity with the serotonin receptor system, working as an antagonistic on 5- $\mathrm{HT}_{2 \mathrm{~A}}$ receptors, ${ }^{95,96}$ and a partial agonistic on $5-\mathrm{HT}_{2 \mathrm{C}}$ and $5-\mathrm{HT}_{1 \mathrm{a}}$ receptors. ${ }^{97}$ Despite the lack of randomized double-blind and placebo-controlled studies, since 2004 more than 200 cases in at least 25 mostly open studies have been published, reporting good efficacy of aripiprazole in the treatment of tics for both adults and children..$^{95,98-120}$ For instance, one larger retrospective study describes tic reduction in 29 of the 37 patients, who all tolerated the drug and continued the treatment. ${ }^{95}$ In general, aripiprazole is well tolerated and side effects (insomnia, fatigue, drowsiness, nausea, tremor, and agitation $^{121}$ ) are usually mild-to-moderate and most often transient. At equivalent doses, aripiprazole is characterized by a safer cardiovascular profile than pimozide. ${ }^{23}$ Weight gain during treatment with aripiprazole is controversial, however. While some studies report negligible weight gain, ${ }^{101,117}$ others have described weight increase in $22 \% 0^{95}$ and up to $50 \%{ }^{112}$ of patients. Murphy and colleagues ${ }^{115}$ noticed a mean increase of $2.3 \mathrm{~kg}$ after a 6-week trial in an open-label, flexible-dose study with 16 children.

Conclusion: Despite the lack of studies with high methodological standards, the treatment of TS with aripiprazole seems possible to recommend as a second choice, due to its unique mechanism of action, its mostly harmless side-effect profile, and the good clinical experiences reported. At least two studies have judged its effectiveness to be superior to that of previous pharmacological treatment options, even in refractory cases..$^{9,98}$

\section{Discussion}

The importance of neuroleptics in the treatment of tics and TS is illustrated by the fact that haloperidol and pimozide are the only drugs that are approved for therapy of these disorders by the FDA. This approval is based on older trials, however. As our research has shown, the trials representing the basis for the pharmacological treatment of TS with typical antipsychotics are rather old and vary in their results and methodological designs. For example, assessments range from subjective self-rating scales of varying complexity to standardized counting of tics based on video recordings. Furthermore, many studies include both children and adults which often results in the suggestion that both groups should be treated in similar ways, apart from drug dosages. At the same time, many experts prescribe these older drugs rather reluctantly due to the nature of their adverse events, especially when treating the typical patient population which consists of children and younger people. In line with this, the few existing guidelines for the pharmacological treatment of tics and $\mathrm{TS}^{9,122-124}$ and helpful papers with treatment advice and suggested strategies ${ }^{11,22}$ mainly recommend the use of atypical antipsychotics as first-line treatment rather than typical neuroleptics. The main reason for this preference for atypical antipsychotics seems to be their different side-effect profiles and their efficacy in the reduction of tic symptoms. But for the example of clozapine, in particular, as the present review shows, it would be wrong to assume this efficacy to be a group effect of antipsychotic agents in general. Among the atypical antipsychotics, risperidone is the best studied agent for the treatment of TS. This, in combination with its positive outcomes, makes this drug, in our and other experts' opinion, first choice. ${ }^{9,22,124}$

Yet this review of the literature shows that there is currently insufficient evidence-based data on the available secondgeneration antipsychotics, apart from risperidone (Figure 1). Maybe the fact that TS in adulthood is a relatively rare disorder could partially explain why the pharmaceutical industry seems to be making only a marginal effort to approve modern antipsychotics for the treatment of TS. This is regrettable especially given the promising results for aripiprazole and olanzapine in methodologically "low level" studies. The efficacy of other promising compounds has not yet been studied either. Asenapine ${ }^{125,126}$ and sertindole ${ }^{127}$ are, based on their mechanism of action, possibly capable of reducing tics. But up to now 


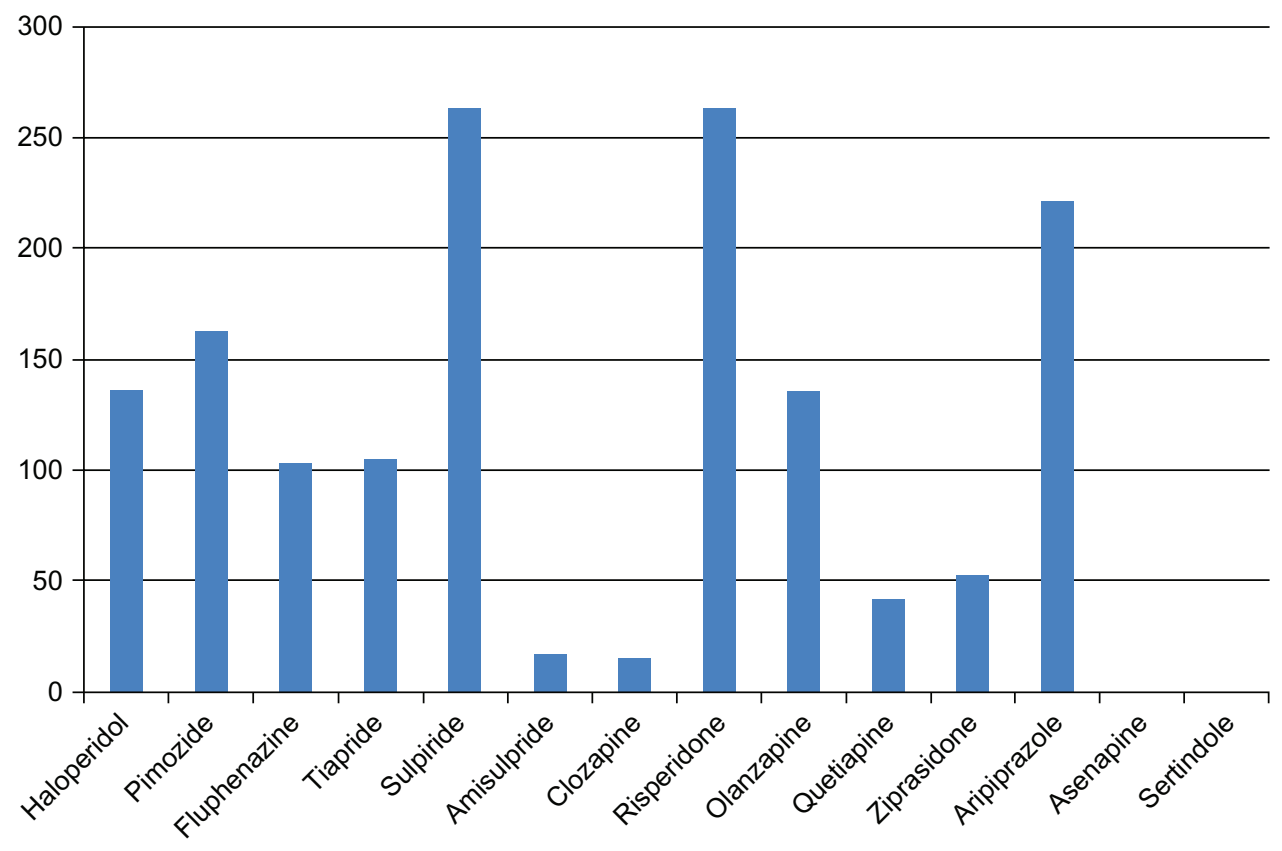

Figure I Number of patients* with TS, treated with each specific agent in studies and case reports published until May $201 \mathrm{I}$.

Notes: *Due to the lack of proper documentation of some of the reviewed studies and limited access to some articles on this topic, the literature review presented here is not exhaustive. The number of patients listed here should therefore be understood as a minimum of patients treated with this drug. It is possible that some of the investigated agents were prescribed to more patients in the context of further studies that were not included in this literature review.

there is no evidence-based information available on these agents in the treatment of TS. Further research is needed.

The usual fluctuation in both severity and nature of symptoms over time, known as "waxing and waning", complicates the objective measurement of symptom severity in studies. In addition, it is necessary to know that long-term treatment with neuroleptic, antiepileptic medication, or stimulants can cause tardive TS, which is characterized by the occurrence of multiple motor and vocal tics as well. ${ }^{128}$ As well as neuroleptics, some experts suggest that alpha-agonists such as clonidine or even guanfacine as first-line therapy have fewer adverse events. ${ }^{129}$ The existing data for these agents are relatively limited, however, and mainly ascribable to smaller, placebo-controlled studies. ${ }^{130,131}$ Thus we lack empirical data in support of alpha-agonists, compared with antipsychotics, and on atypical antipsychotics in general. Large, double-blind, placebo-controlled studies and well executed head-to-head comparisons are urgently required, especially those referring to modern, evidence-based criteria. Multicenter studies and independent, well-trained video-raters could be useful to consider larger numbers of patients, and to collect more reliable information on the reduction of Tourette symptoms.

\section{Limitations}

The fact that we have only searched PubMed could cause a certain bias in the collection of considered publications, but we assume that all relevant papers are available in PubMed because all highly renowned journals are listed in this database. For many agents presented, the data found were too poor to allow any specific conclusions about a drug. We assume this problem to be caused by the generally limited evidence-based data dealing with TS and tics rather than our search criteria.

\section{Acknowledgment}

We thank the Deutsche Forschungsgemeinschaft (KFO219 grant) for financial support.

\section{Disclosure}

K Hardenacke, P Poppe, B Baskin, and C Bartsch report no biomedical financial interests or potential conflicts of interest in this investigation. D Huys reports having received financial assistance for travel to congresses from AstraZeneca. J Kuhn has occasionally received honoraria from AstraZeneca, Lilly, Lundbeck, and Otsuka Pharma for lecturing at conferences and financial support to travel to congresses.

\section{References}

1. Mink JW. Neurobiology of basal ganglia and Tourette syndrome: basal ganglia circuits and thalamocortical outputs. Adv Neurol. 2006; 99:89-98.

2. Jankovic J. Differential diagnosis and etiology of tics. Adv Neurol. 2001;85:15-29. 
3. Wong DF, Brasić JR, Singer HS, et al. Mechanisms of dopaminergic and serotengeric neurotransmission in Tourette syndrome: clues from an in vivo neurochemistry study with PET. Neuropsychopharmacology. 2008:33(6):1239-1251.

4. Wong DF, Singer HS, Brandt J, et al. D2-like dopamine receptor density in Tourette syndrome measured by PET. J Nucl Med. 1997: 38(8):1243-1247.

5. Yoon DY, Gause CD, Leckman JF, Singer HS. Frontal dopaminergic abnormality in Tourette syndrome: a postmortem analysis. $J$ Neurol Sci. 2007:255(1-2):50-56.

6. Yeh CB, Lee CH, Chou YH, Chang CJ, Ma KH, Huang WS. Evaluating dopamine transporter activity with 99 mTc-TRODAT-1 SPECT in drugnaive Tourette's adults. Nucl Med Commun. 2006;27(10):779-784.

7. Yeh CB, Lee CS, Ma KH, Lee MS, Chang CJ, Huang WS. Phasic dysfunction of dopamine transmission in Tourette's syndrome evaluated with (99 m)Tc TRODAT-1 imaging. Psychiatry Res. 2007; 156(1):75-82.

8. Gilbert D. Treatment of children and adolescents with tics and Tourette syndrome. J Child Neurol. 2006;21(8):690-700.

9. Roessner V, Plessen KJ, Rothenberger A, et al. European clinical guidelines for Tourette syndrome and other tic disorders. Part II: pharmacological treatment. Eur Child Adolesc Psychiatry. 2011;20(4): 173-196.

10. Scahill L, Erenberg G, Berlin CM Jr, et al. Contemporary assessment and pharmacotherapy of Tourette syndrome. Neuro Rx. 2006;3(2): 192-206.

11. Singer HS. Treatment of tics and tourette syndrome. Curr Treat Options Neurol. 2010;12(6):539-561.

12. Azrin NH, Nunn RG. Habit reversal: a method of eliminating nervous habits and tics. Behav Res Ther. 1973;11(4):619-628.

13. Kuhn J, Gründler TO, Lenartz D, Sturm V, Klosterkötter J, Huff W. Deep brain stimulation for psychiatric disorders. Dtsch Arztebl Int. 2010;107(7):105-113.

14. Rickards H, Hartley N, Robertson MM. Seignot's paper on the treatment of Tourette's syndrome with haloperidol. Hist Psychiatry. 1997; 8(31 Pt 3):433-436.

15. Parraga HC, Harris KM, Parraga KL, Balen GM, Cruz C. An overview of the treatment of Tourette's disorder and tics. $J$ Child Adolesc Psychopharmacol. 2010;20(4):249-262.

16. Shapiro E, Shapiro AK, Fulop G, et al. Controlled study of haloperidol, pimozide and placebo for the treatment of Gilles de la Tourette's syndrome. Arch Gen Psychiatry. 1989;46(8):722-730.

17. Shapiro AK, Shapiro ES, Young JG, Feinberg TE. Gilles de la Tourette Syndrome. 2nd ed. New York: Raven Press; 1988.

18. Ross MS, Moldofsky H. A comparison of pimozide and haloperidol in the treatment of Gilles de la Tourette's syndrome. Am J Psychiatry. 1978;135(5):585-587.

19. Sallee FR, Nesbitt L, Jackson C, et al. Relative efficacy of haloperidol and pimozide in children and adolescents with Tourette's disorder. Am J Psychiatry. 1997;154(8):1057-1062.

20. Sandor P, Musisi S, Moldofsky H, Lang A. Tourette syndrome: a follow-up study. J Clin Psychopharmacol. 1990;10(3):197-199.

21. Borison RL, Ang L, Hamilton WJ, Diamond BI, Davis JM. Treatment approaches in Gilles de la Tourette syndrome. Brain Res Bull. 1983; 11(2):205-208.

22. Eddy CM, Rickards HE, Cavanna AE. Treatment strategies for tics in Tourette syndrome. Ther Adv Neurol Disord. 2011;4(1):25-45.

23. Gulisano M, Cali PV, Cavanna AE, Eddy C, Rickards H, Rizzo R. Cardiovascular safety of aripiprazole and pimozide in young patients with Tourette syndrome. Neurol Sci. 2011;32(6):1213-1217.

24. Pringsheim T, Marras C. Pimozide for tics in Tourette's syndrome. Cochrane Database Syst Rev. 2009;(2):CD006996.

25. Bruggeman R, van der Linden C, Buitelaar JK, et al. Risperidone versus pimozide in Tourette's disorder: a comparative double-blind parallelgroup study. J Clin Psychiatry. 2001;62(1):50-56.

26. Gilbert DL, Batterson JR, Sethuraman G, Sallee FR. Tic reduction with risperidone versus pimozide in a randomized, double-blind, crossover trial. J Am Acad Child Adolesc Psychiatry. 2004;43(2):206-214.
27. Silay YS, Vuong KD, Jankovic J. The efficacy and safety of fluphenazine in patients with Tourette syndrome. Neurology. 2004;62(Suppl 5): A506.

28. Jankovic J, Jimenez-Shahed J, Brown LW. A randomised, double-blind, placebo-controlled study of topiramate in the treatment of Tourette syndrome. J Neurol Neurosurg Psychiatry. 2009;81(1):70-73.

29. Borison RL, Ang L, Chang S, Dysken M, Comaty JE, Davis JM. New pharmacological approaches in the treatment of Tourette syndrome. Adv Neurol. 1982;35:377-382.

30. Goetz CG, Tanner CM, Klawans HL. Fluphenazine and multifocal tic disorders. Arch Neurol. 1984;41(3):271-272.

31. Singer HS, Gammon K, Quaskey S. Haloperidol, fluphenazine and clonidine in Tourette syndrome: controversies in treatment. Pediatr Neurosci. 1985-1986;(2)12:71-74.

32. Müller-Vahl KR. The benzamides tiapride, sulpiride, and amisulpride in treatment of Tourette's syndrome. Nervenarzt. 2007;78(3):264-271.

33. Dose M, Lange HW. The benzamine tiapride: treatment of extrapyramidal motor and other clinical syndromes. Pharmacopsychiatry. 2000; 33(1):19-27.

34. Meisel A, Winter C, Zschenderlein R, Arnold G. Tourette syndrome: efficient treatment with ziprasidone and normalization of body weight in a patient with excessive weight gain under tiapride. Mov Disord. 2004;19(8):991-992.

35. Scatton B, Cohen C, Perrault G, et al. The preclinical pharmacologic profile of tiapride. Eur Psychiatry. 2001;16 Suppl 1:29s-34s.

36. Bock N, Moll GH, Wicker M, et al. Early administration of tiapride to young rats without long-lasting changes in the development of the dopaminergic system. Pharmacopsychiatry. 2004;37(4):163-167.

37. Drtilkova I. Clonazepam, clonidine and tiapride in children with tic disorder. Homeostasis. 1996;37(5):216.

38. Klepel H, Gebelt H, Koch RD, Tzenow H. Treatment of extrapyramidal hyperkineses in childhood with tiapride. Psychiatr Neurol Med Psychol (Leipz). 1988;40(9):516-522.

39. Lipcsey A. Gilles de la Tourette's disease. Sem Hop. 1983;59(10): 695-696.

40. Eggers C, Rothenberger A, Berghaus U. Clinical and neurobiological findings in children suffering from tic disease following treatment with tiapride. Eur Arch Psychiatry Neurol Sci. 1988;237(4):223-229.

41. Pani L, Gessa GL. The substituted benzamides and their clinical potential on dysthymia and on the negative symptoms of schizophrenia. Mol Psychiatry. 2002;7(3):247-253.

42. Yvonneau M, Bezard P. Apropos of a case of Gilles de la Tourette's disease blocked by sulpiride. Psycho-biological study. Encephale. 1970; 59(5):439-459

43. Ruther E, Degner D, Munzel U. Antidepressant action of sulpiride. Results of a placebo-controlled double-blind trial. Pharmacopsychiatry. 1999;32(4):127-135.

44. Robertson MM, Schneider V, Lees AJ. Management of Gilles de la Tourette syndrome using sulpiride. Clin Neuropsychopharmacol. 1990;13(3):229-235.

45. Huang TL, Lu CY. Correlations between weight changes and lipid profile changes in schizophrenic patients after antipsychotics therapy. Chang Gung Med J. 2007;30(1):26-32.

46. Wetterling T, Mussigbrodt HE. Weight gain: side effect of atypical neuroleptics? J Clin Psychopharmacol. 1999;19(4):316-321.

47. Ho CS, Chen HJ, Chiu NC, Shen EY, Lue HC. Short-term sulpiride treatment of children and adolescents with Tourette syndrome or chronic tic disorder. J Formos Med Assoc. 2009;108(10): 788-793.

48. George MS, Trimble MR, Robertson MM. Fluvoxamine and sulpiride in comorbid obsessive-compulsive disorder and Gilles-De-La-Tourette syndrome. Hum Psychopharmacol Clin Exp. 1993;8:327-334.

49. Trillet M, Moreau T, Dalery J, de Villard R, Aimard G. Treatment of Gilles de la Tourette's disease with amisulpride. Presse Med. 1990; 19(4): 175 .

50. Fountoulakis KN, Iacovides A, St Kaprinis G. Successful treatment of Tourette's disorder with amisulpride. Ann Pharmacother. 2004; 38(5):901. 
51. Kozian R, Friedrich M. Gilles-de-la-Tourette Syndrome as a Tardive Dyskinesia. Psychiatr Prax. 2007;34(5):253-254.

52. Crilly J. The history of clozapine and its emergence in the US market: a review and analysis. Hist Psychiatry. 2007;18(1):39-60.

53. Jaffe E, Tremeau F, Sharif Z, Reider R. Clozapine in tardive Tourette syndrome. Biol Psychiatry. 1995;38(3):196-197.

54. Kalian M, Lerner V, Goldman M. Atypical variants of tardive dyskinesia, treated by a combination of clozapine with propanolol and clozapine with tetrabenazine. J Nerv Ment Dis. 1993;181(10):649-651.

55. Caine ED, Polinsky RJ, Kartzinel R, Ebert MH. The trial use of clozapine for abnormal involuntary movement disorders. Am J Psychiatry. 1979;136(3):317-320.

56. Begum M. Clozapine-induced stuttering, facial tics and myoclonic seizures: a case report. Aust N Z J Psychiatry. 2005;39(3):202.

57. Bastiampillai T, Dhillon R, Mohindra R. Exacerbation of tics secondary to clozapine therapy. Aust N Z J Psychiatry. 2008;42(12):1068-1070.

58. Kim BN, Lee CB, Hwang JW, Shin MS, Cho SC. Effectiveness and safety of risperidone for children and adolescents with chronic tic or tourette disorders in Korea. J Child Adolesc Psychopharmacol. 2005;15(2):318-324.

59. van der Linden C, Bruggeman R, van Woerkom TC. Serotonin-dopamine antagonist and Gilles de la Tourette's syndrome: an open pilot dosetitration study with risperidone. Mov Disord. 1994;9(6):687-688.

60. Diantoniis MR, Henry KM, Partridge PA, Soucar E. Tics and risperidone. J Am Acad Child Adolesc Psychiatry. 1996;35(7):839-840.

61. Stamenkovic M, Aschauer H, Kasper S. Risperidone for Tourette's syndrome. Lancet. 1994;344(8936):1577-1578.

62. Zhao H, Zhu Y. Risperidone in the treatment of Tourette syndrome. Ment Health J. 2003;17:30.

63. Scahill L, Leckman JF, Schultz RT, Katsovich L, Peterson BS. A placebo-controlled trial of risperidone in Tourette syndrome. Neurology. 2003;60(7):1130-1135.

64. Dion Y, Annable L, Sandor P, Chouinard G. Risperidone in the treatment of tourette syndrome: a double-blind, placebo-controlled trial. J Clin Psychopharmacol. 2002;22(1):31-39.

65. Lim LK, Shin SY. Risperidone versus Haloperidol in the treatment of children with Tourette's Syndrome and chronic motor or vocal tic disorder in Korea. Eur Neuropsychopharacol. 2006;16:5527.

66. Gaffney GR, Perry PJ, Lund BC, Bever-Stille KA, Arndt S, Kuperman S. Risperidone versus clonidine in the treatment of children and adolescents with Tourette's syndrome. J Am Acad Child Adolesc Psychiatry. 2002;41(3):330-336.

67. Bruun RD, Budman CL. Risperidone as a treatment for Tourette's syndrome. J Clin Psychiatry. 1996;57(1):29-31.

68. Lombroso PJ, Scahill L, King RA, et al. Risperidone treatment of children and adolescents with chronic tic disorders: a preliminary report. J Am Acad Child Adolesc Psychiatry. 1995;34(9):1147-1152.

69. Shulman LM, Singer C, Weiner WJ. Risperidone in Gilles de la Tourette syndrome. Neurology. 1995;45(7):1419.

70. Robertson MM, Scull DA, Eapen V, Trimble MR. Risperidone in the treatment of Tourette syndrome: a retrospective case note study. Psychopharmacol. 1996;10(4):317-320.

71. Chappell PB, Leckman JF, Riddle MA. The pharmacological treatment of tic disorders. Child Adolesc Psychiatric Clin North Am. 1995;4: 197-216.

72. Giakas WJ. Risperidone treatment for a Tourette's disorder patient with comorbid obsessive-compulsive disorder. Am J Psychiatry. 1995; 152(7):1097-1098.

73. Sandor P, Stephens RJ. Risperidone treatment of aggressive behavior in children with Tourette syndrome. J Clin Psychopharmacol. 2000; 20(6):710-712.

74. Pappadopulos E, Woolston S, Chait A, Perkins M, Connor DF, Jensen PS. Pharmacotherapy of aggression in children and adolescents: efficacy and effect size. J Can Acad Child Adolesc Psychiatry. 2006; 15(1): 27-39.

75. Stephens RJ, Bassel C, Sandor P. Olanzapine in the treatment of aggression and tics in children with Tourette's syndrome-a pilot study. JChild Adolescent Psychopharmacol. 2004;14(2):255-266.
76. Budman CL, Gayer A, Lesser M, Shi Q, Bruun RD. An open-label study of the treatment efficacy of olanzapine for Tourette's disorder. $J$ Clin Psychiatry. 2001;62(4):290-294.

77. McCracken JT, Suddath R, Chang S, Thakur S, Piacentini J. Effectiveness and tolerability of open label olanzapine in children and adolescents with Tourette syndrome. J Child Adolesc Psychopharmacol. 2008;18(5):501-508.

78. http://www.lilly.com. Zyprexa product label. Available from: http:// pi.lilly.com/us/zyprexa-pi.pdf. Accessed September 28, 2011.

79. Ji WD, Li Y, Li N, Guo BY. Olanzapine for treatment of Tourette syndrome: a double-blind randomized controlled trial. Chinese J Clin Rehab. 2005;9:66-68.

80. Onofrj M, Paci C, D'Andreamatteo G, Toma L. Olanzapine in severe Gilles de la Tourette syndrome: a 52-week double-blind cross-over study vs low-dose pimozide. $J$ Neurol. 2000;247(6):443-446.

81. Bengi Semerci Z. Olanzapine in Tourette's disorder. J Am Acad Child Adolesc Psychiatry. 2000;39(2):140.

82. Bhadrinath BR. Olanzapine in Tourette syndrome. Br J Psychiatry. 1998;172:366.

83. Karam-Hage M, Ghaziuddin N. Olanzapine in Tourette's disorder. J Am Acad Child Adolesc Psychiatry. 2000;39(2):139.

84. Lucas Taracena MT, Montanes Rada F. Olanzapine in Tourette's syndrome: a report of three cases. Actas Esp Psiquiatr. 2002;30(2): 129-132.

85. Krishnamoorthy J, King BH. Open-label olanzapine treatment in five preadolescent children. $J$ Child Adolesc Psychopharmacol. 1998;8(2):107-113.

86. Stamenkovic M, Schindler SD, Aschauer HN, et al. Effective openlabel treatment of tourette's disorder with olanzapine. Int Clin Psychopharmacol. 2000;15(1):23-28.

87. Parraga HC, Parraga MI, Woodward RL, Fenning PA. Quetiapine treatment of children with Tourette's syndrome: report of two cases. J Child Adolesc Psychopharmacol. 2001;11(2):187-191.

88. Mukaddes NM, Abali O. Quetiapine treatment of children and adolescents with Tourette's disorder. J Child Adolesc Psychopharmacol. 2003;13(3):295-299.

89. Copur M, Arpaci B, Demir T, Narin H. Clinical effectiveness of quetiapine in children and adolescents with Tourette's syndrome: a retrospective case-note survey. Clin Drug Investig. 2007;27(2): $123-130$.

90. Keck PE Jr, McElroy SL, Arnold LM. Ziprasidone: a new atypical antipsychotic. Expert Opin Pharmacother. 2001;2(6): 1033-1042.

91. Sallee FR, Kurlan R, Goetz CG, et al. Ziprasidone treatment of children and adolescents with Tourette's syndrome: a pilot study. JAm Acad Child Adolesc Psychiatry. 2000;39(3):292-299.

92. Stahl SM, Shayegan DK. The psychopharmacology of ziprasidone: receptor-binding properties and real-world psychiatric practice. J Clin Psychiatry. 2003;64 Suppl 19:6-12.

93. Sallee FR, Miceli JJ, Tensfeldt T, Robarge L, Wilner K, Patel NC. Single-dose pharmacokinetics and safety of ziprasidone in children and adolescents. J Am Acad Child Adolesc Psychiatry. 45(6):720-728.

94. Willmund G, Lee AH, Wertenauer F, et al. Vocal tics associated with ziprasidone. J Clin Psychopharmacol. 2009;29(6):611-612.

95. Budman C, Coffey BJ, Shechter R, et al. Aripiprazole in children and adolescents with Tourette disorder with and without explosive outbursts. J Child Adolesc Psychopharmacol. 2008;18(5):509-515.

96. Wood M, Reavill C. Aripiprazole acts as a selective dopamine D2 receptor partial agonist. Expert Opin Investig Drugs. 2007;16(6): $771-775$.

97. Jordan S, Koprivica V, Chen R, Tottori K, Kikuchi T, Altar CA. The antipsychotic aripiprazole is a potent, partial agonist at the human 5-HT1A receptor. Eur J Pharmacol. 2002;441(3):137-140.

98. Ben Djebara M, Worbe Y, Schopbach M, Hartmann A. Aripiprazole: a treatment for severe coprolalia in "refractrory" Gilles de la Tourette syndrome. Mov Disord. 2008;15;23(3):438-440.

99. Bubl E, Perlov E, Tebartz Van Elst L. Aripiprazole in patients with Tourette syndrome. World J Biol Psychiatry. 2006;7(2):123-125. 
100. Constant EL, Borras L, Seghers A. Aripiprazole is effective in the treatment of Tourette's disorder. Int J Neuropsychopharmacol. 2006; 9(6):773-774.

101. Cui YH, Zheng Y, Yang YP, Liu J, Li J. Effectiveness and tolerability of aripiprazole in children and adolescents with Tourette's disorder: a pilot study in China. J Child Adolesc Psychopharmacol. 2010;20(4): 291-298.

102. Davies L, Stern JS, Agrawal N, Robertson MM. A case series of patients with Tourette's syndrome in the United Kingdom treated with aripiprazole. Hum Psychopharmacol. 2006;21(7):447-453.

103. Dehning S, Riedel M, Muller N. Aripiprazole in a patient vulnerable to adverse reactions. Am J Psychiatry. 2005;162(3):625.

104. Duane DD. Aripiprazole in childhood and adolescence for Tourette syndrome. J Child Neurol. 2006;21(4):358.

105. Fountoulakis KN, Siamouli M, Kantartzis S, Panagiotidis P, Iacovides A, Kaprinis GS. Acute dystonia with low-dosage aripiprazole in Tourette's disorder. Ann Pharmacother. 2006;40(4): 775-777.

106. Hood KK, Lourival BN, Beasley PJ, Lobis R, Pravdova, I. Case study: severe self-injurious behavior in comorbid Tourette's disorder and OCD. J Am Acad Child Adolesc Psychiatry. 2004;43(10): 1296-1303.

107. Hounie A, De Mathis A, Sampaio AS, Mercadante MT. Aripiprazole and Tourette syndrome. Rev Bras Psiquiatr. 2004;26(3):213.

108. Ikenouchi-Sugita A, Yoshimura R, Hayashi K, et al. A case of lateonset Tourette's disorder successfully treated with aripiprazole: view from blood levels of catecholamine metabolites and brainderived neurotrophic factor (BDNF). World J Biol Psychiatry. 2009; 10(4 Pt 3):977-980.

109. Kastrup A, Schlotter W, Plewnia C, Bartels M. Treatment of tics in tourette syndrome with aripiprazole. J Clin Psychopharmacol. 2005; 25(1):94-96.

110. Kawohl W, Schneider F, Vernaleken I, Neuner I. Aripiprazole in the pharmacotherapy of Gilles de la Tourette syndrome in adult patients. World J Biol Psychiatry. 2009;10(4 Pt 3):827-831.

111. Kawohl W, Schneider F, Vernaleken I, Neuner I. Chronic motor tic disorder and aripiprazole. J Neuropsychiatry Clin Neurosci. 2009; 21(2):224.

112. Lyon GJ, Samar S, Jummani R, et al. Aripiprazole in children and adolescents with Tourette's disorder: an open-label safety and tolerability study. J Child Adolesc Psychopharmacol. 2009;19(6): 623-633.

113. Miranda CM, Castiglioni TC. Aripiprazole for the treatment of Tourette syndrome. Experience in 10 patients. Rev Med Chil. 2007; 135(6):773-776.

114. Murphy TK, Bengtson MA, Soto O, et al. Case series on the use of aripiprazole for Tourette syndrome. Int J Neuropsychopharmacol. 2005;8(3):489-490.

115. Murphy TK, Mutch PJ, Reid JM, et al. Open label aripiprazole in the treatment of youth with tic disorders. J Child Adolesc Psychopharmacol. 2009;19(4):441-447.
116. Padala PR, Qadri SF, Madaan V. Aripiprazole for the treatment of Tourette's disorder. Prim Care Companion J Clin Psychiatry. 2005; 7(6):296-299.

117. Seo WS, Sung HM, Sea HS, Bai DS. Aripiprazole treatment of children and adolescents with Tourette disorder or chronic tic disorder. J Child Adolesc Psychopharmacol. 2008;18(2):197-205.

118. Winter C, Heinz A, Kupsch A, Strohle A. Aripiprazole in a case presenting with tourette syndrome and obsessive-compulsive disorder. J Clin Psychopharm. 2008;28(4):452-454.

119. Yoo HK, Choi SH, Park S, Wang HR, Hong JP, Kim CY. An openlabel study of the efficacy and tolerability of aripiprazole for children and adolescents with tic disorders. J Clin Psychiatry. 2007;68(7): 1088-1093.

120. Yoo HK, Kim JY, Kim CY. A pilot study of aripiprazole in children and adolescents with Tourette's disorder. J ChildAdolesc Psychopharmacol. 2006;16(4):505-506.

121. Pae CU. A review of the safety and tolerability of aripiprazole. Expert Opin Drug Saf. 2009;8(3):373-386.

122. Müller-Vahl KR, Rothenberger A, Roessner V, Poewe W, Vingerhoets F, Münchau A. Guidelines for diagnosis and treatment: Tic disorders. In: Diener HC, Putzki N, editors. Guidelines for Diagnosis and Therapy in Neurology. Stuttgart, Thieme; 2008:125-129. German.

123. Rothenberger A, Banaschewski T, Roessner V. Tic disorders. German Society for Child and Adolescent Psychiatry PuP, editor. Guidelines for Diagnosis and Treatment of Mental Disorders in Infancy, Childhood and Adolescence. Köln, Deutscher Ärzteverlag; 2007:319-325. German.

124. http://www.dgn.org. Guidelines of the German Society for Neurology: Available from: http://www.dgn.org/images/stories/dgn/leitlinien/ LL2008/1108kap_012.pdf. Accessed August 12, 2011. German.

125. Shahid M, Walker GB, Zorn SH, Wong EH. Asenapine: A novel psychopharmacologic agent with a unique human receptor signature. J Psychopharmacol. 2009;23(1):65-73.

126. Pompili M, Venturini P, Innamorati M, et al. The role of asenapine in the treatment of manic or mixed states associated with bipolar I disorder. Neuropsychiatr Dis Treat. 2011;7:259-265.

127. Azorin JM, Kaladjian A, Fakra E, Adida M. Sertindole for the treatment of schizophrenia. Expert Opin Pharmacother. 2010;11(18): 3053-3064.

128. Fountoulakis KN, Samara M, Siapera M, Iacovides A. Tardive Tourettelike syndrome: a systematic review. Int Clin Psychopharmacol. 2011; 26(5):237-242.

129. Jankovic J, Kurlan R. Tourette syndrome: evolving concepts. Mov Disord. 2011;26(6):1149-1156.

130. Scahill L, Chappell PB, Kim YS, et al. A placebo controlled study of guanfacine in the treatment of children with tic disorders and attention deficit hyperactivity disorder. Am J Psychiatry. 2001;158(7): 1067-1074.

131. Cummings DD, Singer HS, Krieger M, et al. Neuropsychiatric effects of guanfacine in children with mild tourette syndrome: a pilot study. Clin Neuropharmacol. 2002;25(6):325-332.
Neuropsychiatric Disease and Treatment

\section{Publish your work in this journal}

Neuropsychiatric Disease and Treatment is an international, peerreviewed journal of clinical therapeutics and pharmacology focusing on concise rapid reporting of clinical or pre-clinical studies on a range of neuropsychiatric and neurological disorders. This journal is indexed on PubMed Central, the 'PsycINFO' database and CAS, and is the official

\section{Dovepress}

journal of The International Neuropsychiatric Association (INA). The manuscript management system is completely online and includes a very quick and fair peer-review system, which is all easy to use. Visit http://www.dovepress.com/testimonials.php to read real quotes from published authors. 